\title{
Study on the Financial Risk of the Artwork Investment Market
}

\author{
Jian Wang ${ }^{1,2, *}$ \\ ${ }^{I}$ Institute of Art and Design, Changsha University of Science and Technology, Changsha 410114, Hunan, China; \\ ${ }^{2}$ College of Art and Design, Wuhan University of Technology, Wuhan 430079, Hubei, China
}

\begin{abstract}
Rising prices of art, dazzling market size and transaction data, an endless stream of art investment projects, both reflect the enthusiasm of the art market investment. The work of art is the spiritual product of the creation of human beings. It has the value of art, history and economy. The art market from a small minority of cultural market a jump to the vision of public investors, which is the art market as a field of investment and financial markets combined with the results. Developing the Chinese art and finance market is a very important step for Chinese art and financial docking. This paper studies the risk of the financial development of the art investment market and gives some suggestions.
\end{abstract}

Keywords: Artwork, financial risk, investment market.

\section{BACKGROUND AND INTRODUCTION}

Study on art investment market is the earliest can be traced back to 1904 Crowninshield Frederic, Commercialism in the Arts [1], he summed up the art most commodity trading phenomenon, it is pointed out that the art trade in addition to the realization of the basic collection and aesthetic value, but also has realized the function of economic interests, for the first time, the economic significance of art trade. In the same year published in the Journal of the Royal Society of Arts, report the Art-trade schools in Germany [2] also shows that at the beginning of the 20th century, the art market has through pure development of the cultural circle of the commercial in nature, have the character of "market". In 1912 State Henry also in the Business-Man in art [3] the points that a kind of people exist in the art market at that time, collection is not they are buying works of art for the main purpose, through art trading profit is their pursuit. At that time, this behavior has the nature of investment.

Domestic art investment market is about 80 years after the reform and opening up, and so the study of art investment is starting late. In 1993, Hong Kong University of Henry M. K. Mok, Vivian W. K. Ko, sauna S. M. woo et al in modern Chinese painting and calligraphy works of income calculated earlier on the art market of the investment analysis. In 2010, Wang Yi in the art market pricing mechanism of the price of paintings more may influence factors carries on the statistical test, and the hedonic price model works pricing analysis, show the works size and paintings prices are positively related, and painting is fixed price in the process of the main influence factors. Sun Wei, Yang Chunming in 2006 in China art investment in the rapid growth of the causes and risk analysis [4], the article pointed out that
China art investment market, the rapid growth is mainly due to the economic development, the property market downturn, art anti economic cycle of strong interaction and, at the same time, we should pay attention to the risk of investing in art, including art market is not standardized, hard to determine the authenticity of the art, art value and price is difficult to unify, art return cycle is difficult to determine. Hu Jing, Zan Sheng Feng on artwork price formation mechanism and investment strategy [5], a text that is mainly affected by the art self nature, market demand, works of art investment and speculative value, show off consumption four factors of art prices in 2008. Tao $\mathrm{Yu}$ in 2009 in the "international art investment fund theory and practice" [6] the article summarizes the international art investment fund operation mode, strategy and risk, has very good enlightenment on the art of China's financial. Xi Mu in the process of China's art market financial analysis [7] for the commercialization of art, assets, trust, capital, securities of five stages and analyzes the characteristics of different stages of the artwork market financial of 2009. Chen Ye 2011 in the domestic art investment finance perspective, [8] the analysis of the current situation of domestic and overseas art market and pointed out that the liquidity, pricing, experience, the perception of the public and government management is the bottleneck of our country the development of the art market, the liquidity is the biggest obstacle to the development of the market. Mai Xiaocong, Tao Tian in 2010 in the financial crisis of art investment, [9] this paper believes that China's art market although the development impetus is not decreased, but still in a certain extent received the impact of the financial crisis, that art investment exist in larger bubbles, and suggested that we should promote art finance. Liu Xiangyu in 2012 in "China's art market trend and art characteristics of financial analysis" [10] to analyze the development of China's art market in the paper, pointed out some outstanding performance including art investment funds, the frequent exchange of art securitization theory research, cultural property exchange, set up the national policy; at the same time he 


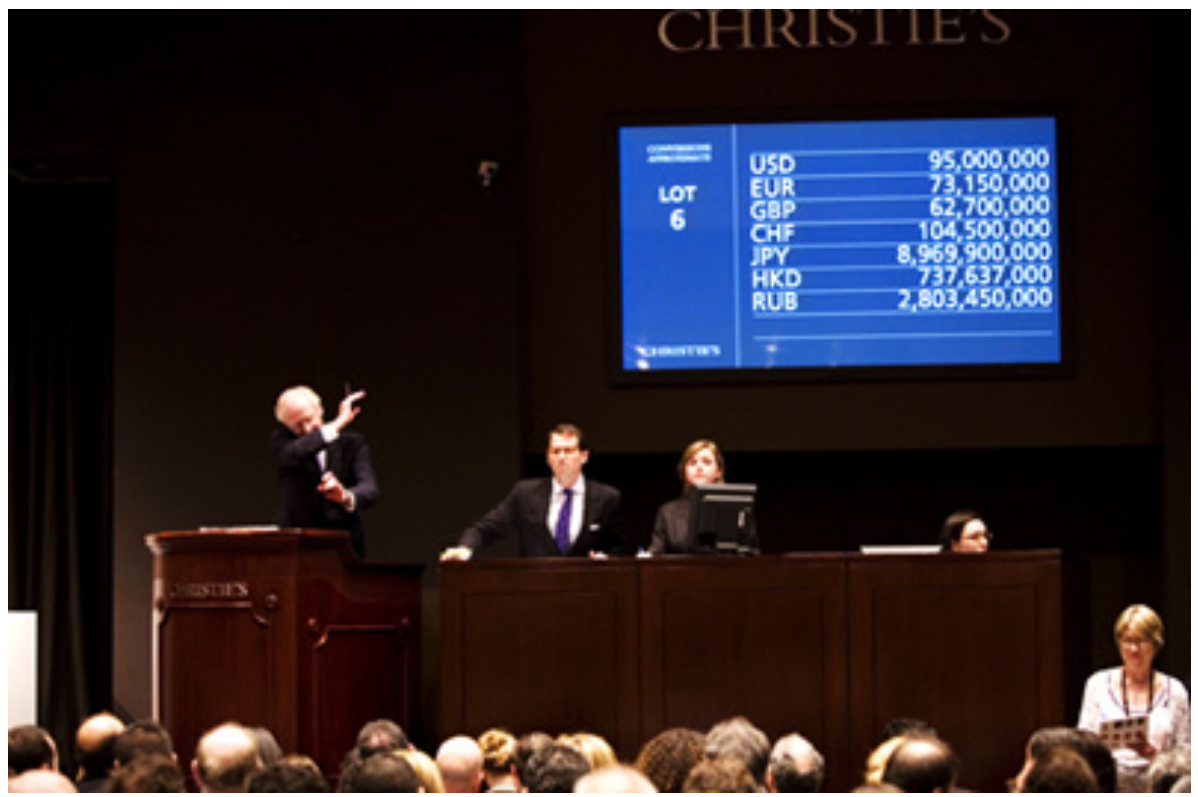

Fig. (1). The scene of art auction.

pointed out that China's art market has emerged the trend of financial development, performance for the auction, the scale of the six aspects for commissions, information channels, financial institutions, art service circulation, market participants, some financial characteristics and the modern art works presented; in addition, he also analyzes five problems to solve the road requires the presence of art financial in our country, as shown in Fig. (1).

In summary, the research for the art investment market has been involved in financial problem, the financial markets, but mainly to market investment institutions as a clue to analyze, for the development of future financial problems no systematic analysis and in the study on the risk of the financial development is still blank.

\section{RISK OF THE FINANCIAL INVESTMENT IN THE ART MARKET}

The combination of art market and the financial market is the inevitable trend of the future development of art investment and finance can effectively break impede art investment market development of liquidity is low and high threshold of professional knowledge, capital threshold high the bottleneck problem, between the art market and the general public investors set up bridge, open a vast capital world of art investment market, and financial can discover the art market value and promote the popularization of art and cultural knowledge. But art investment and financial development cannot be eager to hope for success, the road is full of thorns, need to proceed with caution, pay attention to risk prevention.

Financial artwork of for the majority does not have the appreciation of professional knowledge of ordinary investors to open the gate to the art investment market, art market opened the inflow of funds into the door, but in the open the door at the same time also brought new risks one by one on excessive financial risk. The excessive finance refers to the process of the work of the art investment, the development of the investment is too fast and so that the value of art itself is the basis of value.. Financial investment art regardless of how to develop, and basic value of the investment subject of bearing body will eventually fall in real works of art, price fluctuations in the market despite the influence of many factors, but ultimately the determining factor is still as the underlying value of the artwork itself. From the art value of finance will be twisted into a capital game, leading to market bubble generation and accumulation, once the bubble burst, the development of art investment market will cause a heavy blow. However financial process oriented and aimed at is investors that do not have professional knowledge of appreciation, is will art academic value and the investment value of separation, the design of financial products and services is taking the opportunity of requirements, really have the knowledge of professional appreciation of works of art collectors and investors of the financial products and services demand is not big, that is to say, the financial products and services to the buyers do not understand or are too fond of art, this shows the financial process itself has been hidden risk of blind speculation.

\subsection{Speculation Makes the Game of Pass the Parcel is Over}

Artwork investment products regardless of how the packaging, the basic mode is to buy high priced at low prices to sell to obtain income, but this price is not sustainable. Art is different from stock, stock prices rose behind with the operating performance of the business entity as a support, low to buy high and sell the return value creation in dividends, and art prices rise is not supported. A piece of art, once completed, its academic value and artistic value has been determined, although historical value may change with the development of society has, but this change usually across time, time is very long, in a specific historical period, the historical value of a work of art is almost unchanged. So the artwork is not containing any new value after the completion, which means that the impetus that supports the price of the artwork 
is not there. For today's art market frequently create astronomical mythology behind the more is hype and marketing funds to promote play a role in, when speculation and capital to push up prices exceed the value of art in itself, would be a bubble began to accumulate, when prices rose to no investors are willing to take over when the bubble bursts, then pass the parcel game is over, the victim is the bubble burst last are stuck high investors, as shown in Fig. (2).

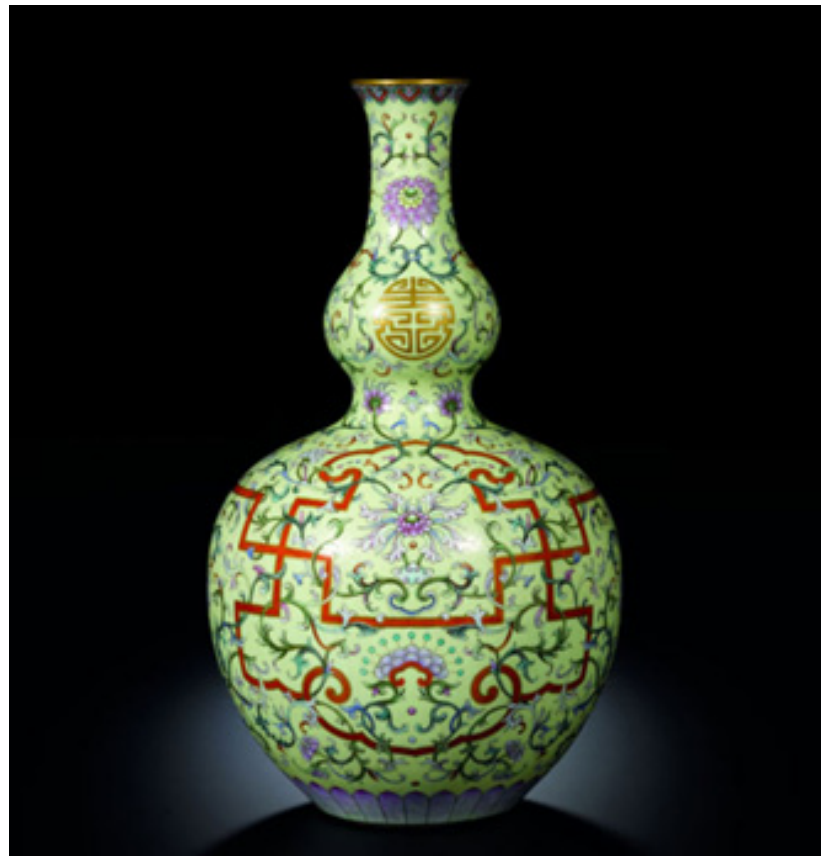

Fig. (2). Sky-high price of art work: the qing dynasty qianlong long necked bottle gourd.

\subsection{Short Term Operation}

Art investment is the most suitable for the long-term investment, but the introduction of financial products are mostly short-term products. Since the launch from the China Minsheng Bank domestic debut in the true sense of the art fund, a large number of works of Art Fund, trust project emerge in endlessly, the duration of the project but 2-3 years, and some are even only 12 months, more than 5 years of investment projects almost nothing. In contrast, foreign art fund, closed for 8-10 years. Thus the domestic art market is more impetuous, over the pursuit of short-term gains, a departure from the investment characteristics of the work of art itself. If you do not pay attention to risk prevention is extremely easy to evolve for capital speculation market is flooded with the bad state.

\subsection{Market Inversion}

Health of the art market should be a clear secondary market division of their duties of market, market level, including Gallery, art galleries, art dealers and art fair, and that a major role is to cultivate and featured artists, the secondary market, including art dealers and auction companies, are fulltime in a small boutique market transactions. But at present, the phenomenon of the one or two grade market inversion is very serious in our country, the market function is absent, and the two markets are over development. 2011 China's auction industry association deputy secretary General Zheng
Xinyao admitted: "the total volume of the Chinese art market in 2010 blowout, but Gallery occupies the share quite weak, little effect and the lack of voice, secondary market upside down the phenomenon is very serious. There is no art market in the galleries, is a crazy market. [11] Many of the auction house and the artist directly contact collection works, skip the promotion of the gallery, directly to the auction of the artists without the work of the auction market. Without the cultivation of artists many aspiring young artists, works of maturity and artistic value has not been evaluated by the market, so a direct push secondary market if you want to shoot higher prices will inevitably need to through the packaging, the packaging process is the risk of hidden points. Many non senior buyers due to the appreciation of professional knowledge is not fine, lack of understanding of art, lack of confidence to participate in a market transaction, and hold the auction house auction will be fine cognitive, are more susceptible to the packaging works blinded, once to buy auction after the market assessment package after the true value to be lower than the purchase price, will suffer losses. Continuously for a long time, Sotheby's reputation will be damaged, blow to the confidence of investment on the secondary market, the market order, there will be chaos, chaos results may modify reversal phenomenon in the secondary market, but let the market spontaneous experience painful correction than at first pay attention to the risk, positive and healthy guidance, as shown in Fig. (3).

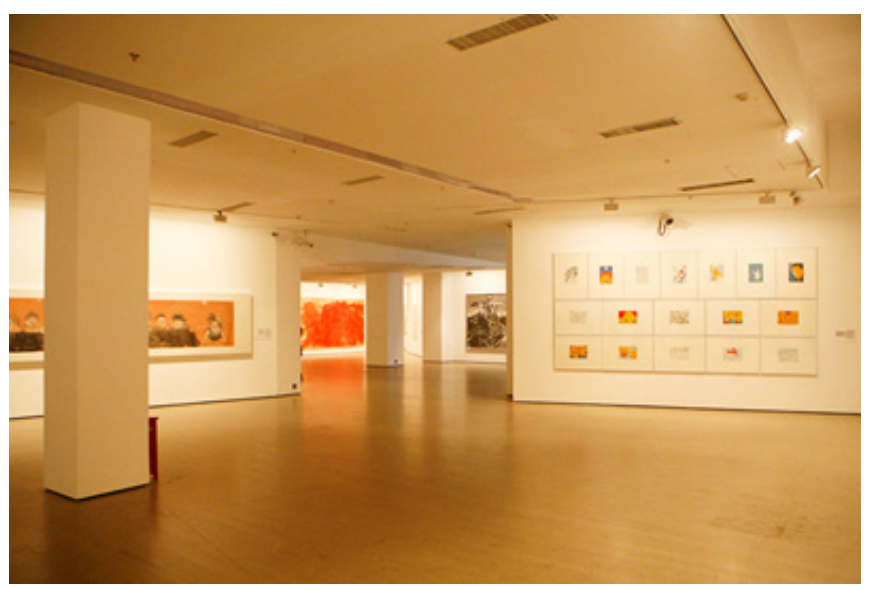

Fig. (3). Empty china exhibition.

\subsection{False Trade}

The value of the artwork is expensive, the capital of the art market is also very high, the amount of a transaction involved hundreds of millions, so that the scale of the fund is clearly also attracted the eyes of the fraud. Fraud includes two layers of meaning: one is that art forgery, namely, the fake; II refers to the acts of business sales of art forgery, namely false transactions. as shown in Fig. (4).

The case of art fraud has been ancient times; the most serious fraud in our art market is mainly concentrated in calligraphy and painting, porcelain, furniture and jade. Expo, exchange exhibition and has introduced the identification of art TV programs and fake appear frequency high in that serious fraud in the art market. In the fake and false trading emerge in an endless stream, bad behavior has seriously affected the healthy development of the art market. 


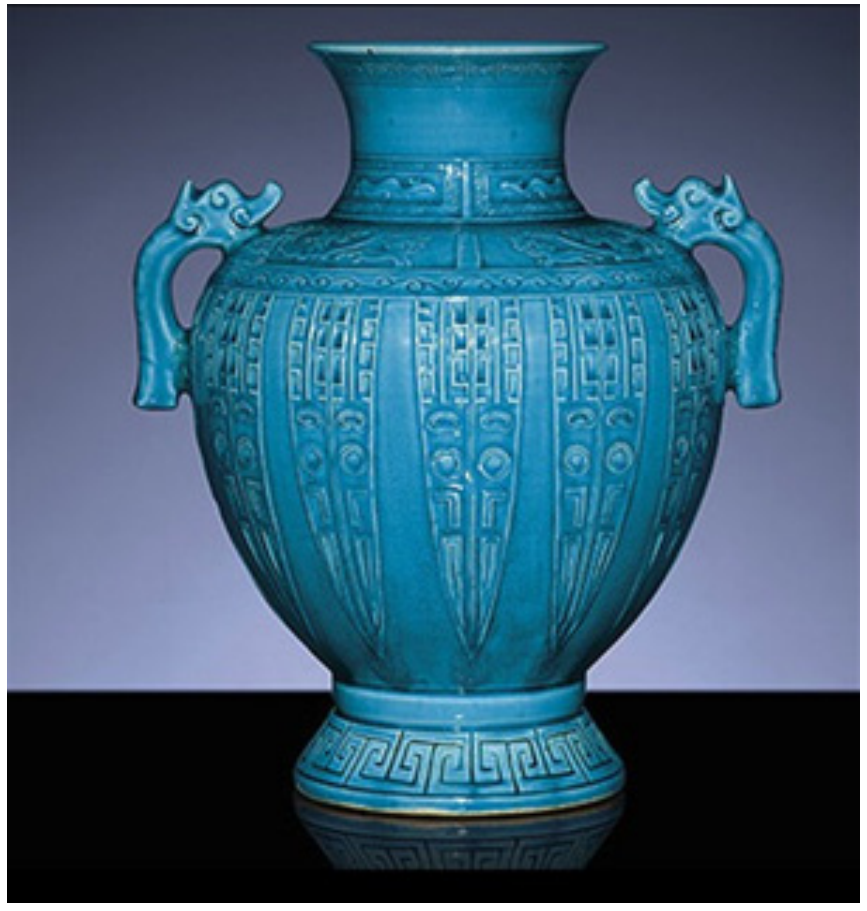

Fig. (4). The fake artwork mix the spurious with the genuine.

The root cause of the serious fraud is the low cost, high risk and low risk. As shown in Table 1, once after it fake is sold as genuine, the benefits are far greater than the cost of fraud. And art authenticity is a profound professional knowledge, even with years of experience of investors from time to time be deceived, the forgery was discovered probability is small. In addition, the most common way of art transactions is the auction, and the international practice is that the auction house for the authenticity of the auction is not responsible for the authenticity of the goods. Under this background, the auction house shoot fake events that were not in the minority, many of the auctions even in the knowledge that the auction is a fake still are without scruple the ground arsis. At present, the attention of the art forgery is not enough, and the investigation is not the artist personally I point out the forgery, the fraud is hard to be valued, if you are found counterfeit artwork, usually in violation of copyright crime conviction. According to Chinese copyright infringement crime law, illegal income more than 30000 Yuan or illegal business amount of 50000 Yuan or above, copy product quantity of a thousand above can be sentenced to three years of impris- onment or criminal detention; illegal income of 15 million Yuan of above or illegal business amount of 25 million Yuan more than copy product quantity of 5000 copies above can be sentenced to seven years imprisonment. Visible even if the maximum sentence of punishment still not too heavy, which makes forged a dynamic risk of a stroke, because failure would be subject to the punishment obviously is not successful, will receive the temptation of profit large. Need to curb counterfeit increase investigate strength and punishment, for the eagle fakes to impose heavy fines, for false trading dealers, auction houses and the implementation of accountability.

\subsection{The Moral Hazard of the Principal-agent Relation- ship between the Investors and the Investment Agency}

Prior to the introduction of financial products and services, investors and the art market is direct contact, finance to establish a medium of exchange in the middle of the investors and the art market, the direct relationship between the two in order to indirect relation to deal the relationship between the media and investors change in order to direct relationship, which is a kind of principal-agent relation. Medium of exchange market, including a variety of bank mentioned above, the art fund, art trust, insurance companies and other institutions, investors in the selection by these institutions are investing in art, the principal-agent relationship of the two established and investment institutions to investors of the commission entrusted responsibility, in business investment or should be in the interests of the investors for the first. But by China's stock market often burst out "rat" visible, contrary to the entrusted agent relationship is not uncommon, works of art investment market, the situation is not different. Therefore, this kind of entrust agency relation behind the moral hazard problem still worthy of attention. Methods to resolve should aim to reduce the information asymmetry, through strengthen relevant laws and regulations and establish a supervision mechanism to of a strong institutional party control, security information in the interests of the minority investors.

\section{SOLUTION}

Art insurance value and value to the work of art, the security of art transactions, collections and exhibition, the health of the art market has a positive sense.

Table 1. A part of fake price in chengdu art market [12].

\begin{tabular}{|c|c|c|}
\hline Place of Sale & The Name of Works & The Signature of Works \\
\hline \hline A antique treasures line & Landscape painting & Wang shimin \\
\hline An antique shop & Chang Yi Shu Shan Tu & Zhang daqian \\
\hline A gallery & Guan Shan Qiu Se Tu & Huang binhong \\
\hline A gallery & Antithetical couplet, \\
central scroll etc. & Zeng guofan, \\
\hline
\end{tabular}


The introduction of the insurance market is a powerful weapon against counterfeit. Rampant fakes in the art market is about the discoloration has always been a topic, but also seriously affected the healthy development of the art market ills. The intervention of professional insurance companies, from the side to strengthen the authenticity of occupational and professional judgment, can be in a certain extent curb fakes entering the market. Foreign art insurance is so popular that it almost becomes the additional insurance lock, since the insurance company can not take their own risks and interests to joke, in other words, to get the artwork from the market point of view, its effectiveness equivalent to a certificate of additional certification. In this sense, the meaning of art point value and the value of insurance is not.

Art insurance facilitates trading, collection and display. With the development of our country economy, the domestic art market is hot, astronomical art is constantly photographed, art "running" into the billion era, the safety of art will pay close attention to the work. Whether art is by personal collection or collections, safety is always the first one, and if you take out or exhibition to the auction market transactions, need more security measures, which include the art of insurance.

In developed countries the art of insurance is a very popular types of insurance, foreign insurance companies are generally set up the insurance business of art, in the international industry relatively well-known is AXA insurance responsible for art insurance company AXA art insurance, coverage includes not only art theft after compensation, is also responsible for compensation for damage to works of art. Before the mouth, AXA art insurance in Belgium, France, Germany, Italy, Spain, Switzerland, the United Kingdom and China provide insurance services for the works of art. [13]

Domestic insurance companies do not have professional art insurance business. Past paintings and other works of art like cash, the insurance company's conventional property insurance policies as there are exclusions. Therefore, although several companies such as Paul and other companies have done some art underwriting business, but does not belong to the true sense of art insurance. In the past few years, domestic insurance companies by referring to foreign experience, has with the types of insurance, such as Ping An insurance has been launched "art comprehensive insurance", mainly cover some modern calligraphy and painting, sculpture and porcelain, but precious of ancient paintings and other works of art, "special agreement". At the same time, due to the art of the insured amount is relatively high in general, domestic insurance companies underwriting must to the international reinsurance market protection.

Domestic art insurance why it is difficult to expand, particularly as family property insurance, the additional risk given the promotion, art insurance is still stuck in the narrow scope of the exhibition and auction insurance, can not be widely to individual open, and the personal insurance business of art or almost blank. The reason for this lies mainly in the domestic art evaluation system can not be quantification and identification of art talent lack, both supply and demand not mature, and is difficult to distinguish the authenticity of the resulting, value difficult estimate etc. These problems involve and wide, is not only related to the legal system design and technical operation, more deep cultural concept and the whole social background to act provides the possibility.

\section{CONCLUSION}

In a word, the art Financial of influence on the development of the art market is, and at the same time, a great, and will for the development of Chinese art market and the rise of bring historic opportunity.

The first is to greatly reduce the art investment barriers to entry, let the Chinese art market investment can get rapid development in a short period of time, to meet the diversified investment demand of social capital, also can meet our growing financial needs.

Second is to bring the art market and the prosperity and development of intermediate industry. Because the market demand increases, the art trade volume increased considerably, auction company business is hot, galleries and art dealers, art criticism, art appraisal, art media related businesses will perk up.

Third is the cultural and art property exchange is come into being. The auction is a main channel of the art trade; the channel is the gallery and anecdotal exchanges. The main function of art and cultural property rights exchange is for collectors and consumers and art institutions to build a trading platform.

Fourth is to better promote the deepening of our cultural system reform. To establish a modern system of cultural industries, modern cultural market system need more capital to enter, which can make capital can in resource integration, industrial integration, market activation play a positive role.

\section{CONFLICT OF INTEREST}

The author confirms that this article content has no conflict of interest.

\section{ACKNOWLEDGEMENTS}

Declared none.

\section{REFERENCES}

[1] C. Frederic,"Commercialism in the," International Monthly, vol. 9, pp. 129-139, 1904.

[2] Y. Chunming, and S. Wei, "Art-tra de schools in Germany,"Journal of the Royal Society of Arts, vol. 53, pp. 171-171, 1904.

[3] S. Henry, "The business-man in Art," Academy and Literature, vol. 82, pp. 783-784, 1912.

[4] Y. Chunming, and S. Wei, "The cause and risk analysis of rapid growth of artwork investment in China," Infrastructure Optimization, vol. 12, pp. 74-76, 2006.

[5] H. Jing, and Z. Shengfeng, "Art price formation mechanism and investment strategy,"Cultural industries, vol. 2, pp. 61-65, 2008.

[6] T. Yu, "Theory and practice of international art investment fund," Art observation, vol. 2, pp. 127-130, 2009.

[7] X. Mu, "The analysis of the process of the Chinese art market," Art market, vol. 6, pp. 77-79, 2009.

[8] C. Ye, "Domestic art investment financial sector perspective," Shanghai Finance, vol. 4, pp. 17-27, 2011.

[9] M. Xiaocong, and T. Tian, "Artwork investment under the financial crisis," Commercial economics, vol. 24, no. 10, pp. 84-86, 2010. 
[10] L. Xiangyu, "The trend of art market and financial characteristics of art," Cultural industry research, vol. 5, pp. 149-153, 2012.

[11] Xu Yue, "There is no art market to participate in the art market, is a crazy market,"Yangcheng Evening News, 2011.
[12] M. Jian, "The risk of artwork and its Evasion," Art and investment, vol. 11, pp. 1-15, 2011.

[13] W. Guocai, "The visible giant business opportunity," China Securities Journal, vol. 2, pp. 7,21, 2008.

Received: June 10, 2015

Revised: July 29, 2015

Accepted: August 15,2015

(C) Jian Wang; Licensee Bentham Open.

This is an open access article licensed under the terms of the (https://creativecommons.org/licenses/by/4.0/legalcode), which permits unrestricted, noncommercial use, distribution and reproduction in any medium, provided the work is properly cited. 